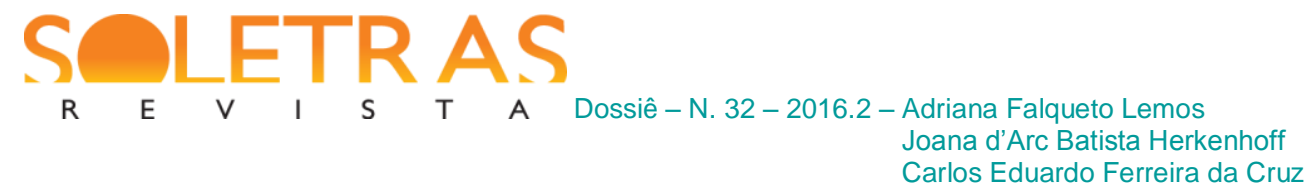

\title{
A violência e a tragédia em God of war
}

\author{
Adriana Falqueto Lemos ${ }^{1}$ \\ Instituto Federal do Espírito Santo \\ Joana d'Arc Batista Herkenhoff ${ }^{2}$ \\ Secretaria Municipal de Educação de Serra \\ Carlos Eduardo Ferreira da $\mathrm{Cruz}^{3}$ \\ Instituto Federal do Rio Grande do Norte
}

Resumo: Objetivou-se, a partir do viés da crítica literária, refletir sobre a presença ostensiva da violência no videogame God of War (2005), da Sony. A partir dos estudos sobre o modo ficcional trágico, desenvolvidos por Northrop Frye em Anatomy of Criticism (1957), buscouse evidenciar a presença de elementos da tragédia na arquitetura do jogo e suas implicações na produção de sentidos por parte dos jogadores, uma vez que se compreende o game como um artefato cultural que comporta valores e ideologias. Assim sendo, os jogadores não são meros consumidores e podem se aperceber dessas questões por meio de uma leitura crítica que pode ser empreendida a partir do jogar (BOGOST, 2011). A partir da análise do game com o aporte teórico indicado, foi possível identificar também a presença de elementos da epopeia ao lado de diversos aspectos do gênero literário trágico na conformação narrativa do videogame em questão. São esses elementos: a semelhança do protagonista com o herói trágico, a ironia do destino, a falha trágica e a catarse. Constatou-se que a violência, como recurso utilizado pelos designers do jogo, integra-se de forma coerente à estrutura do game, contribuindo para o envolvimento do jogador em uma obra que se destaca por sua já reconhecida qualidade.

Palavras-chave: Videogame. God of War. Catarse. Tragédia.

\footnotetext{
${ }^{1}$ Graduada em Letras Inglês pela Universidade Federal do Espírito Santo (2012), Mestre em Letras, também pela UFES (2015). Doutoranda em Letras pelo Programa de Pós-graduação em Letras da UFES. É escritora e professora de Inglês no Instituto Federal do Espírito Santo, Campus Santa Teresa. Faz pesquisa (principalmente) nos seguintes temas: leitura, literatura e videogame. Integrante do Grupo do Núcleo de Estudos Literários e Musicológicos e Núcleo de Estudos de Literatura Anglófona e outras Artes da UFES, membro titular do Comitê de Ética em Pesquisa do Ifes. E-mail: flemos.adriana@gmail.com

${ }^{2}$ Doutoranda em Letras pelo Programa de Pós-graduação em Letras da Universidade Federal do Espírito Santo, onde pesquisa sobre a literatura na educação básica: concepções, práticas e acervos, com apoio da FAPES (Fundação de Amparo à Pesquisa e Inovação do Espírito Santo). É Professora de Língua Portuguesa da Secretaria Municipal de Educação, Serra (ES). Interessa-se pela literatura em sua relação com a cultura, questões étnico-raciais e de gênero. E-mail: joanadbh@terra.com.br

${ }^{3}$ Doutor e Mestre em Linguística Aplicada pela Universidade Estadual do Ceará (UECE). Professor do Instituto Federal do Rio Grande do Norte (IFRN), leciona no ensino técnico, tecnológico e superior. É membro do grupo de pesquisa Pragmática Cultural, Linguagem e Interdisciplinaridade (PRAGMACULT) e atualmente desenvolve pesquisas sobre letramentos não acadêmicos.
} 
Receita para fazer um herói

Tome-se um homem,

Feito de nada, como nós,

E em tamanho natural.

Embeba-se-lhe a carne,

Lentamente,

Duma certeza aguda, irracional,

Intensa como o ódio ou como a fome.

Depois, perto do fim,

Agite-se um pendão

E toque-se um clarim.

Serve-se morto.

(Reinaldo Ferreira,)

É comum ver pais e educadores preocupados com a influência que os jogos com conteúdo violento podem ter no comportamento de crianças e adolescentes, por acreditarem no poder que esses artefatos culturais teriam de torná-los também violentos. Embora seja essa uma visão simplificadora da possível influência direta dos jogos sobre os jogadores, a preocupação não é de todo injustificada, uma vez que uma análise do modo como muitos desses jogos são construídos leva a perceber que não se trata de objetos ingênuos, despidos de valores e construídos meramente para o entretenimento. A leitura do artigo dos games studies, intitulado The Rhetoric of Video Games (2008), no qual Ian Bogost aborda os videogames como objetos culturais que comportam ideologias, valores e visões de mundo, confirma essa ideia:

"Esta é uma distinção importante: videogames não são apenas etapas que facilitam práticas políticas, culturais ou sociais; eles são também meios de cultura onde valores culturais podem ser representados - para crítica, sátira, educação, ou comentário. Quando entendidos dessa forma, podemos aprender a ler jogos como expressões deliberadas de perspectivas individuais. Em outras palavras, jogos de videogame fazem afirmações sobre o mundo, que os jogadores podem compreender, avaliar e deliberar. Os desenvolvedores de jogos criam jogos que constroem expressões deliberadas sobre o mundo. Os jogadores podem aprender a ler e criticar estes modelos, deliberando sobre as implicações de tais verdades" (BOGOST, 2008, p. $119)^{45}$.

4 This is an important distinction: videogames are not just stages that facilitate cultural, social, or political practices; they are also media where cultural values themselves can be represented — for critique, satire, education, or commentary. When understood in this way, we can learn to read games as deliberate 
Designers codificam jogos objetivando proporcionar experiências e essas experiências também estão encadeadas às restrições espaciais do mundo virtual de cada jogo. Tais experiências provocam leituras por parte do jogador, que absorve as informações da tela, do som, do manejo do jogo etc. De acordo com Bogost (2008), portanto, a codificação gera um mecanismo retórico - o jogo, como um todo. A partir disso, o teórico entende que videogames não teriam apenas recursos retóricos visuais, mas sim procedurais, já que os processos de jogo (implicados no código e em funcionamento no jogo) com os quais os jogadores entram em contato são significados embutidos pelos designers.

Nessa perspectiva, Bogost (2008) entende que o espaço virtual dos jogos implica significado, já que define, por meio de um código feito a priori, os limites de atuação e de percepção do jogador. Essas restrições estão impostas durante o processo de codificação (já que o jogo é formatado dentro de um limite tecnológico), assim como quando o código é posto em atividade. Quando jogam, os usuários devem se circunscrever ao universo do game, compreendendo cada jogo como uma experiência num novo mundo virtual. Entretanto, como alerta Bogost (2008, p. 219), “os jogadores podem aprender a ler e criticar estes modelos, deliberando sobre as implicações de tais verdades". Utilizando conceitos barthesianos (BARTHES, 1978), os jogadores podem quebrar a "ilusão referencial" que resulta da manipulação dos signos para gerar "efeitos de real", os quais fazem crer na naturalização do signo.

Isso significaria compreender que os jogos de videogame são portadores de conteúdos ideológicos e axiológicos e, não sendo os sujeitos que os manipulam meros consumidores passivos (CERTEAU, 2011), pode ocorrer uma apropriação não tão inócua por parte dos jogadores; ou seja, uma apropriação que saia dos limites do espaço do jogo para as suas vidas - aliás, essa é uma das insalubridades do jogo. E sábias são as crianças quando dizem "se não sabe brincar, não brinque". Considerando o jogar como forma de interação, envolvem-se, entre os elementos constitutivos, o designer e suas intenções, que se manifestam no jogo (como código em prática) e o jogador, que se apropria do jogo na sua prática de jogar e o lê em sua subjetividade.

expressions of particular perspectives. In other words, video games make claims about the world, which players can understand, evaluate, and deliberate. Game developers can learn to create games that make deliberate expressions about the world. Players can learn to read and critique these models, deliberating the implications of such claims.

5 Esta e outras traduções são de nossa autoria, salvo indicação explícita na bibliografia. 
O videogame God of War, a princípio simplório, apresenta questões que podem ser potencializadas pela crítica literária, considerando que se destacam nesse jogo, assim como em outras mídias contemporâneas, a retomada de elementos da mitologia e da cultura clássica greco-romana, promovendo o cruzamento de valores e temporalidades distintas: o antigo, arcaico, heráldico, eterno com o moderno, o tecnológico, o transitório. Esse aparente paradoxo nos leva a perguntar: o que une um adolescente do século XXI a um guerreiro espartano? As ditas questões inescapáveis da condição humana, considerando que, por baixo da indumentária, todos, em suas diferenças, nascem, amam, odeiam e lutam pela sobrevivência?

God of War, lançado em 2005, foi sucesso de crítica, tendo recebido prêmios como o Jogo do Ano da Academia de Artes Interativas e Ciências (AIAS) em 2006. O game pertence ao gênero action-adventure, que mistura elementos tanto de jogos de ação (interações em tempo real, nas quais os jogadores devem usar os reflexos) e aventura (jogos com resoluções de problemas). Jogos de aventura são mais focados na história e têm menos elementos com os quais os jogadores possam lidar fisicamente. Os jogos do gênero action-adventure têm mais ação e, por conta disso, suas histórias se desenvolvem de maneira mais rápida e dinâmica.

No âmbito do jogo, God of War I resume as ações do jogador em duas frentes: a) matar de maneira sangrenta quaisquer inimigos que surjam na tela, e b) resolver pequenos quebracabeças que se configuram como obstáculos para que o jogador passe para uma fase seguinte ou que abra tesouros com itens para melhorar o seu desempenho.

No âmbito narrativo, Kratos, o personagem principal, recebe vários poderes e armas dos deuses olímpicos, usados para combater figuras que, em sua maioria, são baseadas em seres da mitologia grega. A narrativa (e assim também o jogo) ocorre in media res, ou seja, a ação se inicia em uma fase adiantada dos acontecimentos, privilegiando um momento de impacto para arrebatar o leitor/jogador, sendo a história narrada em forma de flashback. Essa é uma convenção própria da epopeia (MOISÉS, 199, p. 287), sendo reconhecida por Horácio na Odisseia e na Ilíada. 
A primeira cena, com a qual o jogador se depara, é a de um monólogo em que Kratos lamenta o fato de os deuses o terem abandonado; o personagem está numa montanha grega e, ao final da fala, joga-se nas águas do mar 6 .

"E Kratos se jogou da montanha mais alta de toda a Grécia. Dez anos de sofrimento, dez anos de pesadelos intermináveis finalmente chegariam ao fim. A morte seria sua fuga da loucura... [...] Mas nem sempre foi assim, Kratos havia sido uma vez um campeão dos deuses..." (GOD OF WAR, $2005)^{7}$.

A história de Kratos é contada, durante todo o jogo, por uma voz onisciente. Por meio desse narrador se fica sabendo que Kratos era um comandante espartano, líder de um exército de 50 homens que, mesmo invencível contra milhares, é massacrado por uma horda bárbara. Desejando obter a vitória mais uma vez, Kratos oferece a sua vida e serviços a Ares, deus da guerra, em troca da assistência divina. Com a vitória, Kratos passa a servir a Ares e ruma à Grécia, na intenção de conquistar o país. Enquanto passa por pequenas cidades, ele incendeia vilas (é o que acontece quando ele passa por uma pequena cidade que costumava adorar Atena). Kratos, porém, só percebe que sua própria mulher e filha estão entre os residentes assassinados depois que conquista a cidade. Ares afirma que isso era necessário para que o protagonista pudesse ter seus poderes testados e para que perdesse seu último laço com a humanidade. Um oráculo da vila amaldiçoa-o, fazendo com que as cinzas dos mortos pigmentem a sua pele. A partir de então, Kratos renega Ares e passa dez anos servindo ao Olimpo.

O jogador começa a jogar quando Kratos está indo para Atenas, cidade atacada pelo exército de Ares. No mar Egeu, o navio de Kratos é atacado pela Hidra de Lerna. A deusa Atena surge para Kratos, pedindo que ele a ajude a salvar sua cidade; Kratos concorda, sob a condição de que seja liberto de suas memórias e de seus crimes do passado, vendo na libertação uma chance de perdão.

6 Note-se que este texto e os outros textos surgem apenas verbalmente, só surgem escrito em versões traduzidas para o português.

7 And Kratos cast himself from the highest mountain in all of Greece. After 10 years of suffering, 10 years of endless nightmares, it would finally come to an end. Death would be his escape from madness... [...] But it had not always been this way, Kratos had once been a champion of the gods... 
"Kratos: Eu tenho servido fielmente os deuses por dez anos. Quando você vai me libertar desses pesadelos?

Atena: Pedimos uma última tarefa sua, Kratos, o seu maior desafio o aguarda... Em Atenas. Onde meu irmão, Ares, estabelece cerco. Enquanto falamos, Atenas está à beira da destruição. É da vontade de Ares que minha grande cidade caia. Zeus proibiu os deuses de entrar em guerra uns com os outros. É por isso que deve ser você, Kratos. Apenas um mortal, treinado por um deus, tem a chance de derrotar Ares.

Kratos: E se eu for capaz de fazer isso, de matar um deus, então as visões irão acabar?

Atena: Conclua esta tarefa final e o passado que consome você será perdoado. Tenha fé, Kratos, os deuses não se esquecem daqueles que vêm em seu auxílio.

Narrador: Deixando a carcaça podre da Hidra para trás, Kratos lança suas velas mais uma vez. Seu maior desafio e a liberdade da sua loucura crescente estavam diante dele, na antiga cidade... De Atenas... "(GOD OF WAR, $2005)^{8}$.

Kratos vai até a cidade, luta contra inimigos mitológicos e supera obstáculos. Encontra o oráculo, que lhe diz que a caixa de Pandora pode conceder-lhe os poderes necessários para matar um deus, porém, a caixa está escondida num templo nas costas do titã Cronos, a quem Zeus amaldiçoou a viver no deserto das almas perdidas até que as areias retirem toda a carne de seus ossos.

Quando finalmente consegue a caixa, Ares empala Kratos com um pilar e rouba-a. Kratos, porém, consegue reverter seu quadro difícil e volta do Mundo dos Mortos. Ele retorna a Atenas para pegar a caixa de Pandora e confrontar Ares.

${ }^{8}$ Kratos: I have faithfully served the gods for -ten years-. When will you relieve me of these nightmares? / Athena: We request one final task of you Kratos, your greatest challenge awaits... in Athens. Where even now, my brother, Ares lays siege. As we speak, Athens is on the verge of destruction. It is the will of Ares, my great city falls. Zeus has forbidden the gods from waging war on each other. That is why it must be -you-, Kratos. Only a mortal, trained by a god has a chance at defeating Ares. / Kratos: And if I am able to do this, to kill a god, then the visions, they will end? / Athena: Complete this final task, and the past that consumes you will be forgiven. Have faith Kratos, the gods do not forget those who come to their aid. / Narrator: Leaving the rotting carcass of the Hydra behind, Kratos sets sail once more. His greatest challenge, and freedom from his growing madness lay before him, in the ancient city... of Athens... 


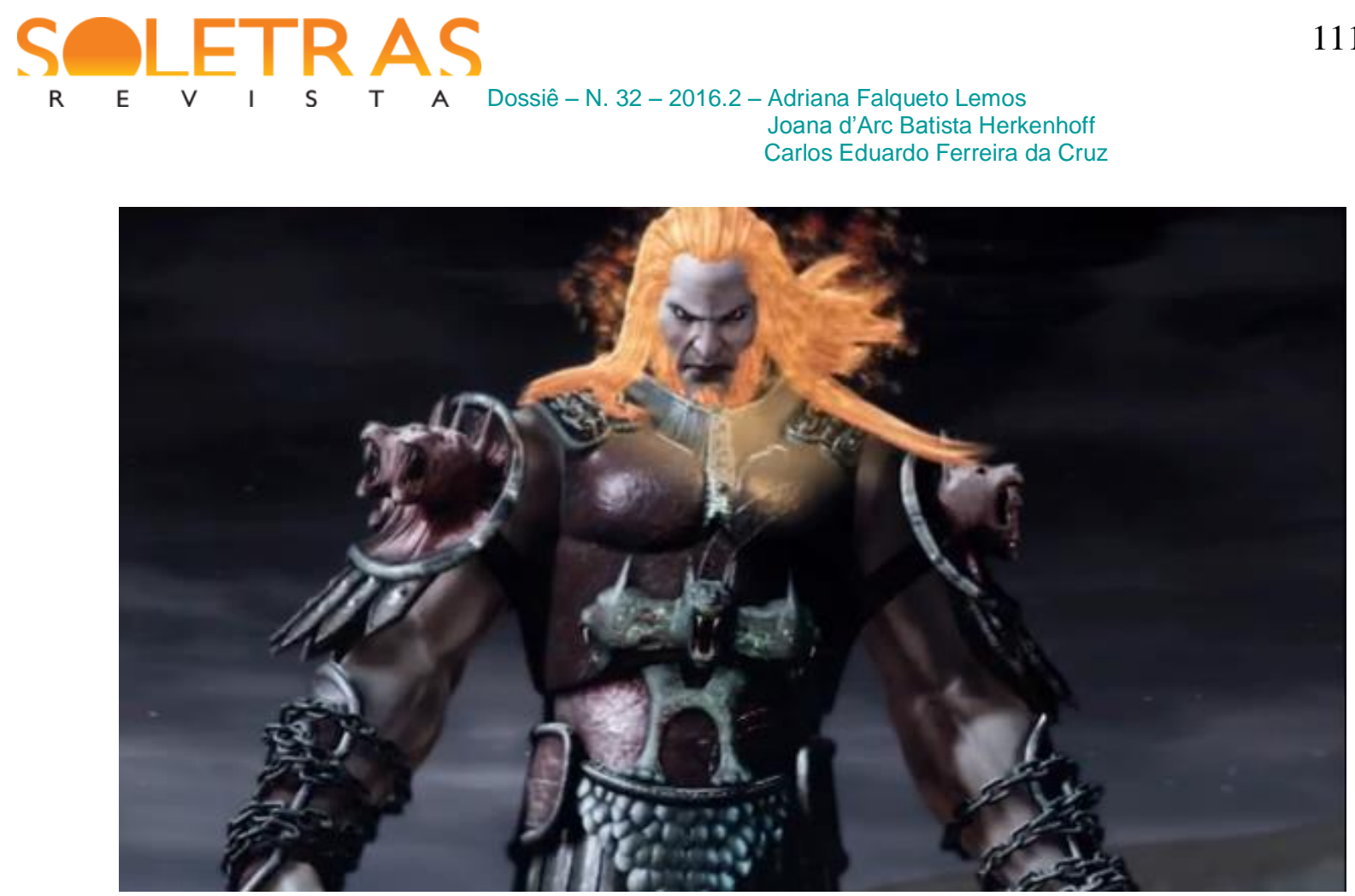

Figura 1 - O deus Ares, de God of War 1.

Fonte: Internet.

Depois de conseguir matar Ares, Kratos volta a conversar com Atena:

"Narrador: Kratos tinha feito o impossível, um mortal havia derrotado um deus, Ares não mais existia... A cidade havia sido salva e iria prosperar novamente. O mesmo não podia ser dito de Kratos, pois a verdade lhe foi revelada quando procurou reconstruir a sua alma com a ajuda dos deuses.

Kratos: Atena, me liberte dessas lembranças que me assombram.

Atena: Você fez bem Kratos, apesar de velarmos a morte de nosso irmão, os deuses estão em dívida com você. Prometemos que seus pecados seriam perdoados, e assim eles o foram, mas nunca prometemos lhe tirar de seus pesadelos. Nenhum homem ou deus poderia esquecer os seus terríveis feitos.

Narrador: No final, sabendo que as visões de seu passado nunca iriam deixálo, Kratos fez o seu caminho para os penhascos, procurando pelo Mar Egeu" (GOD OF WAR, 2005) $)^{9}$.

9 Narrator: Kratos had done the impossible, a mortal defeating a god, Ares was no more... The city had been saved, and would thrive again. The same could not be said for Kratos, for as he sought to rebuild his soul with the help of the gods, the truth was revealed to him. / Kratos: Athena, rid me of the memories that haunt me still. / Athena: You have done well Kratos, though we mourn the death of our brother, the gods are in debt to you. We promised your sins would be forgiven, and so they are, but we never promised to take away your nightmares. No man, no god could ever forget the terrible deads you have done. / Narrator: In the end, knowing that the visions of his past would never leave him, Kratos made his way to the bluffs, overlooking the Aegean Sea. 
A narrativa torna-se circular, já que se encerra no momento em que se inicia. Porém, assim que se encontra com as ondas, Kratos é retirado do mar por Atena e levado até o Olimpo, onde, ao sentar-se num trono, torna-se o deus da guerra.

Instigante, a narrativa do jogo torna significativo o jogar, pois faz com que o personagem principal se revele, aos poucos, aos olhos da audiência. Fica claro que se trata de um homem amargo, atormentado e que mata impiedosamente a todos que se apresentam como empecilho em seu trajeto. Observe o que o narrador tem a dizer sobre Kratos logo quando ele é apresentado aos jogadores, durante a passagem em que ainda está no navio e não foi contatado por Atena:

"Narrador: Abatidas como animais, as vítimas estavam diante dele: uma lembrança do seu próprio passado, um passado do qual ele nunca poderia escapar... Seu único conforto era o mar. Navegando infinitamente de um porto a outro, a serviço dos deuses do Olimpo, todas as suas esperanças estavam com eles. Por que não importava o quanto ele consumia de vinho ou quantas mulheres ele tinha em sua cama, nada no mundo poderia livrá-lo dos horrores que atormentavam a sua mente" (GOD OF WAR, 2005) ${ }^{10}$.

Suas atitudes violentas são, entretanto, amenizadas, ao longo do jogo, pela história cujo desvelar faz com que o personagem possa ser mais bem compreendido pela audiência. Há uma série de artigos sobre videogames que tratam, porém, do exagero da violência apresentada por jogos como God of War. Apesar de esse ser um ponto interessante de análise, esse trabalho encaminha-se para outro horizonte de leitura, que busca compreender o sentido dessa violência na arquitetura do jogo por sua aproximação com os gêneros épico e trágico.

As análises dos jogos de videogame que são feitas hoje normalmente não tomam como ponto de apoio o estudo literário ${ }^{11}$. Em geral, as análises pendem para outros campos de atuação dos estudiosos, como o campo de ciências sociais, por exemplo, ao tratar da análise de ética e de como o jogador se envolve em narrativas que subvertem a ordem moral que há

10 Narrator: Slaughtered like animals, the victims lay before him, a reminder of his own past, a past he could never escape... His only sauness was the sea. Endlessly sailing from one harbor to the next, in service to the Gods of Olympus, all his hopes rested with them. For no matter how much wine he consumed or how many women he took to his bed, nothing on earth could rid him of the horrors that plagued his mind.

11 Uma revisão de pesquisas feitas sobre o estudo do videogame pode ser lida no artigo de Adriana Falqueto Lemos e Maria Amélia Dalvi, "Videogames, leitura e literatura: aproximações bibliográficas multi e transdisciplinares.” (Con)textos Linguísticos, v. 7, p. 6-27, 2013. 
em seu contexto histórico-social. God of War poderia ser um exemplo disso, já que se trata de um jogo no qual há um interesse, por parte dos designers e produtores, de explicitar e exagerar qualquer elemento que possa tornar a experiência do jogo ainda mais violenta.

O interesse dos produtores pela explicitação da violência poderia estar relacionado, possivelmente, com: a) a ideia de que as guerras são, de fato, violentas e visualmente cruéis; b) a ideia de que a representação de uma guerra entre um humano e um deus, no contexto mitológico grego, só pode ser feita através de imagens violentas e exageradas; ou c) a ideia de que um jogo com esse tema deve agradar e alcançar ou superar as expectativas de um público masculino, possivelmente mais interessado em imagens violentas e acostumado com mídias que já se imbricam nesse esquema.

Não havendo interesse em debater a violência imagética do jogo em si, ruma-se para outros dos vários debates que podem ser arguidos frente ao videogame God of War (2005) que não excluem, porém, o conteúdo violento do jogo. Percebe-se que a figura de Kratos se sustenta justamente em sua postura violenta nas cenas de massacre que ele protagoniza, trazendo à cena a figura do herói trágico nos moldes da literatura clássica greco-romana.

Para pensar nesse modelo de herói, representado no universo do videogame, opera-se com a teoria de modelos ficcionais de Northrop Frye, de Anatomy of Criticism (1957).

"Em ficções literárias, o enredo consiste em alguém fazendo algo. O alguém, se um indivíduo, é o herói, e o algo que ele faz ou falha em fazer é o que ele pode fazer, ou o que poderia fazer, no nível das postulações feitas sobre ele pelo autor das consequentes expectativas da audiência. Ficções, no entanto, podem ser classificadas, não moralmente, mas pelo poder de ação do herói, que pode ser maior que o nosso, menor, ou talvez o mesmo" (FRYE, 1957, p. 33$)^{12}$.

Subsequentemente, Frye fala das classificações do herói, dentre as quais dá-se destaque a duas:

12 In literary fictions the plot consists of somebody doing something. The somebody, if an individual, is the hero, and the something he does or fails to do is what he can do, or could have done, on the level of the postulates made about him by the author and the consequent expectations of the audience. Fictions, therefore, may be classified, not morally, but by the hero's power of action, which may be greater than ours, less, or roughly the same (FRYE, 1957, p. 33). 


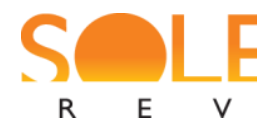

"1. Se superior em espécie, tanto para os outros homens quanto ao meioambiente de outros homens, o herói é um ser divino, e a história sobre ele será um mito, no sentido comum de uma história sobre um deus. Essas histórias têm um lugar importante na literatura, mas se encontram, via de regra, fora das categorias literárias normais. [...] 3. Se superior em grau aos outros homens, mas não ao seu ambiente natural, o herói é um líder. Ele tem autoridade, paixões e poderes de expressão muito maiores do que os nossos, mas o que ele faz está sujeito tanto à crítica social e à ordem da natureza. Esse é o herói do modo altamente mimético, dos mais épicos e trágicos, é principalmente o tipo de herói que Aristóteles tinha em mente" (ibid, pp. 3334 , grifos do autor) ${ }^{13}$.

A partir dessa perspectiva, pode-se situar Kratos como o herói do grupo 3, ou seja, o líder que, mesmo com capacidades incríveis, ainda está sujeito ao contexto no qual está inserido. Apesar de se tratar de uma história mítica e de Kratos conseguir se tornar um deus (o que só acontece ao final da história), o jogador (Kratos?) não experimenta essa sensação superior divina: passa a narrativa inteira se esgueirando por entre as brechas e procurando saídas para os problemas enfrentados pelo protagonista. Os deuses, os verdadeiros superiores aos humanos e ao meio, participam da história como forças que manipulam o protagonista para que ele faça o que é desejado. Apesar de parecer que os deuses têm limitações, é preciso lembrar que a definição de Frye (1957) é clara ao identificar que tipo de poder o herói divino tem: ele é superior aos outros homens. Os deuses de God of War têm limitações apenas perante seus iguais, e não em relação aos homens. Nesse universo, Kratos desempenha o papel já desempenhado por personagens como Aquiles, Belerofonte, Jasão, Perseu, Teseu e Odisseu.

De maneira interessante, o personagem Kratos reúne em sua história elementos que são comuns a outros heróis como o combate ao Minotauro, à Hidra de Lerna, à Medusa, às Górgonas, ao Ciclope, dentre outros. Dessa maneira, Kratos se relaciona com uma tradição de heróis gregos, tanto das tragédias quanto das epopeias, em suas agruras com os deuses, que estão sempre a desafiá-los, subjugá-los e complicar-lhes as vidas. Afinal, "tragédia, no sentido

13 1. If superior in kind both to other men and to the environment of other men, the hero is a divine being, and the story about him will be a myth in the common sense of a story about a god. Such stories have an important place in literature, but are as a rule found outside the normal literary categories. [...] 3. If superior in degree to other men but not to his natural environment, the hero is a leader. He has authority, passions, and powers of expression far greater than ours, but what he does is subject both to social criticism and to the order of the nature. This is the hero of the high mimetic mode, of most epic and tragedy, and is primarily the kind of hero that Aristotle had in mind (FRYE, 1957, pp. 33-34). 
central ou altamente mimético, é a ficção da queda de um líder (ele tem que cair porque essa é a única maneira com a qual um líder pode ser isolado de sua sociedade), mistura o heroico com o irônico" (FRYE, 1957, p. 37) ${ }^{14}$. A tragédia, explica Frye, não está no que a audiência virá a sentir pelos personagens envolvidos, mas na constatação de que algo feito pelo protagonista, que independe de seu status moral, terá consequências completamente inevitáveis (FRYE, 1957, p. 38). Kratos cometeu o erro de desejar a vitória na batalha mais do que sua vida e, ao transformar Ares no mestre de todos os seus atos, teve que suportar o desenrolar dos acontecimentos vindouros; em última análise, alguém que estima mais a vitória em batalha do que a si mesmo não poderá, futuramente, lamentar as consequências da sua escolha. Kratos, tal qual o herói trágico, sofre por suas escolhas erradas, ao passo que, por conta delas, vive andando em círculos.

No episódio em que Kratos destrói a cidade, matando sua própria mulher e filha, podese identificar elementos que aproximam o game do gênero trágico em que "o herói, sujeito ao império dos deuses, era constrangido pelas circunstâncias a cometer uma falha que o arrasta à desgraça" (MOISÉS, 1999, p. 2873). Também aí está presente a "ironia do destino", considerando que Kratos foi advertido e, ao ignorar a advertência, incorre no erro fatal que resulta na morte da esposa e filha.

A capacidade de promover a identificação e o envolvimento do espectador/leitor, característica do gênero trágico, também pode ser observada em God of War, o ato de jogar o jogo possibilita à audiência a sensação de frustração constante a qual Kratos é submetido. Há um esforço para que um caminho inteiro seja percorrido e a audiência acredita que, por exemplo, quando chegar à cidade de Atenas será possível confrontar Ares e fazer o que a deusa Atena pediu; o que ocorre, na realidade, é uma postergação: Kratos terá que ir até outro lugar para procurar o que precisa. Isso acontece de maneira circular e ao longo de todo o jogo; chega-se ao lugar onde era necessário chegar, mas não se encontra o que se procurava, ou encontra-se quem gostaria, mas, efetivamente, não se realiza o que se pretendia. Até o final, quando o jogador conduz Kratos na superação de todos os seus desafios físicos e mentais, a deusa lhe nega a faculdade do esquecimento do passado.

14 Tragedy in the central or high mimetic sense, is the fiction of the fall of a leader (he has to fall because that is the only way in which a leader can be isolated from his society), mingles the heroic with the ironic" (FRYE, 1957, p. 37). 
Pode-se inferir que houve um mal-entendido, uma lacuna entre o que Kratos desejava quando concordou em fazer o que Atena queria e o que ela realmente poderia fazer por ele; de qualquer maneira, chega-se ao final da história e encontra-se a tragédia: seus feitos são perdoados, mas não esquecidos. Qual foi, então, o ganho de Kratos e do jogador? Ascender como deus da guerra? Será que era isso o que ele desejava? Será que para ser um deus da guerra é necessário o perdão pelos feitos, mas não o esquecimento deles? Para ser um deus da guerra é importante que se sofra com as lembranças dos próprios feitos?

Talvez o que se entenda por guerra, dentro do universo ficcional representativo do jogo, possa ser relacionado com a imagem de pessoas que lutam por vingança, por raiva ou por justiça, mas nunca eximidas de seus feitos. Ao final, pode ser que o jogador seja perdoado das várias mortes que ajudou a cometer quando controlou Kratos ao longo do caminho, mas ele não as esquecerá, assim como o seu protagonista. O fato de o jogo não conceder ao anti-herói seu almejado prêmio - o esquecimento do fato de que matou a esposa e a filha - indica um desfecho moralizante (supreendentemente moralizante para um jogo deveras violento e até mesmo sádico), além de um retorno à ordem.

O jogo se configura como uma tragédia anunciada: no prólogo é-nos apresentada a história do de Kratos que, ao final do breve introito, lança-se ao precipício. O jogo inicia-se em flash back, ocupando o jogador o lugar do herói trágico: joga, sabendo que seu fim é certo: a autopunição pela morte. Ele mata, mas sabe que, por isso, morrerá. Não se trata de um jogo de influências diretas, como "o adolescente que jogar esse jogo se tornará violento". O jogo é muito mais complexo e indicia um design que pode lidar com estratégias civilizatórias arquetípicas longevas e de eficácia comprovada: a catarse.

Pode-se discutir o fato de que, ao mesmo tempo em que se assemelha a essa tradição de heróis épicos e trágicos, Kratos se afasta deles, pois, diferentemente de todos os outros, é capaz de matar um deus. A morte de um deus mitológico pelas mãos de um herói mortal é um importante elemento da narrativa que pode produzir questionamentos e discussões sobre quebra de paradigmas, relação do homem com a divindade, porém, não se estenderá às apreciações sobre o jogo nesse sentido.

Nesta discussão, buscou-se refletir, mesmo que brevemente, sobre a presença de elementos atinentes aos gêneros trágicos e épicos no game em análise, e sobre como o jogo,

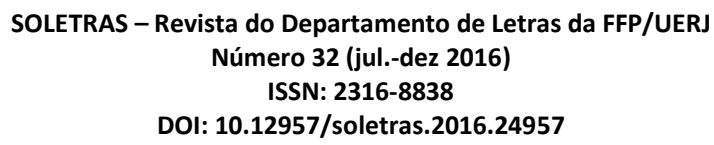


no seu jogar, revela-se através da atuação e leitura do jogador, encerrando conceitos e visões de mundo.

Conquanto não sejam desprezíveis as preocupações de pais e educadores para com a pretensa influência exercida pelos jogos violentos na formação de crianças e adolescentes, o aporte teórico da crítica literária amplia essa discussão ao possibilitar compreender que a configuração do game como avizinhado ao gênero trágico, opera com um mecanismo sofisticado (a catarse que, ao contrário do que se pensa, assegura a conformação do indivíduo ao establishment).

Posteriormente, pode ser interessante procurar entender $\mathrm{o}$ fato de mídias contemporâneas como videogame utilizarem modos ficcionais tão antigos como a tragédia. Possíveis respostas já começam a surgir com artigos como "God of War: A Narrative Analysis” (2013), de Robert Cassar. Por hora, pontua-se, finalmente, o valor da arquitetura do game: a análise favorecida pela leitura do mesmo, em sua relação com o gênero literário trágico, possibilitou constatar que a violência visual do jogo se justifica, ficando perfeitamente clara a necessidade da gratuidade aparente do imagético brutal: a crueza da violência é necessária para que possa fazer sentido à pungente necessidade de esquecimento por parte do protagonista: só através da violência é que a narrativa se justifica. No âmbito do jogo, quando os designers dizem ao jogador que é impossível que se esqueça de algo, colocase em xeque o final idealizado pelo jogador (e projetado, talvez, pela proposta de Atena), da busca pela resolução dos problemas e do final feliz. Frustra, possivelmente, a audiência que, intimamente, pode se questionar e refletir sobre o jogo, sobre os valores em jogo nesse objeto cultural muitas vezes desvalorizado diante da monumentalidade dos clássicos.

\section{Referências}

BARTHES, Roland. O efeito do real. In: BARTHES, Roland et al. Literatura e semiologia. Petrópolis: Vozes, 1972 (35-44).

BOGOST, Ian. The Rhetoric of Video Games. In: SALEN, Katie. The Ecology of Games: Connecting Youth, Games, and Learning. The John D. and Catherine T. MacArthur Foundation Series on Digital Media and Learning. Cambridge, MA: The MIT Press, 2008. 117-140. 

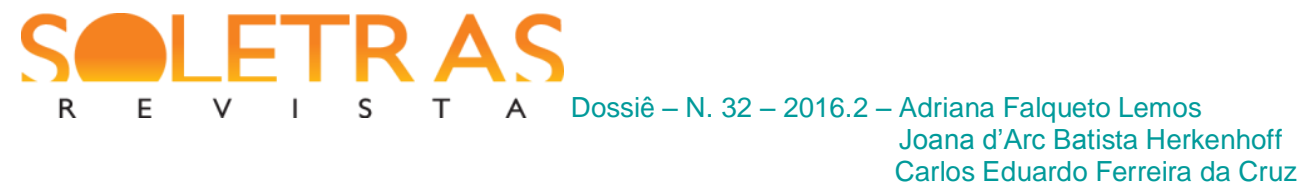

CASSAR, Robert. God of War: A Narrative Analysis. In: Eludamos. Journal for Computer Game Culture. 2013; 7 (1), pp. 81-99.

FRYE, Northrop Herman. Anatomy of Criticism. New Jersey: Princeton U. Press, 1957.

SONY. God of War, 2005.

MOISÉS, Massaud. In Media res. In: MOISÉS, Massaud. Dicionário de termos literários. 14. ed. São Paulo: Cultrix, 1999. p. 287-288.

CERTEAU, Michel de. Ler: uma operação de caça. In: CERTEAU, Michel de. A invenção do cotidiano: 1. Artes de fazer. Trad. Ephraim Alves. 17. ed. Petrópolis, RJ: Vozes, 2011, p. 236248

\section{Violence and tragedy in God of war}

Abstract: The objective of the discussion brought on this paper is to reflect on the ostensible presence of violence in the video game God of War (2005), by Sony, under the scope of literary criticism. Taking the studies of the tragic mode, developed by Northrop Frye in Anatomy of Criticism (1957), the study aims to highlight the presence of tragic elements in the game architecture and their implications for the production of meaning by the players. For this, we understand the game as a cultural artifact that holds values and ideologies, so the players are not mere consumers and can realize these issues through a critical reading (BOGOST, 2011). Using this theoretical framework, it is possible to identify the presence of epic elements alongside various aspects of the tragic genre in the narrative that shapes the game in question. The elements are: the similarity of the protagonist with the tragic hero, the irony of fate, the tragic flaw and catharsis. It was found that violence is a resource used by the game's designers that integrates consistently the game structure contributing to the involvement of the player in a work that stands out for its already renowned quality.

Key words: Videogame. God of War. Catharsis. Tragedy.

Recebido em: 04 de agosto de 2016.

Aprovado em: 13 de janeiro de 2017. 